\title{
Indices of Oxygen Saturation in Urban and Rural Children
}

\author{
Olena Dmytrotsa0*1, Yanko N², Shvayko ${ }^{1}$, Poruchynskiy A ${ }^{1}$ and Zhuravlov0 ${ }^{1}$ \\ ${ }^{1}$ Lesia Ukrainka Eastern European National University, Ukraine \\ ${ }^{2}$ SI Volyn Regional Laboratory Center of the MOH of Ukraine, Ukraine
}

Received: May 05, 2018; Published: May 11, 2018

*Corresponding author: Olena Dmytrotsa, Lesia Ukrainka Eastern European National University, Ukraine

\section{Introduction}

In recent years, there has been a significant deterioration in the health of children in different regions of Ukraine, which is manifested primarily by various morph functional disorders. According to many scholars, the poor health of children and adolescents in Ukraine is due to inappropriate nutrition, lifestyle, unfavorable socio-economic trends and unfavorable environmental factors $[1,2]$. Therefore, the issue of health development is an important part of a comprehensive assessment of the schoolchildren's health. According to the scientific sources, a tendency towards a decrease in the number of physically healthy schoolchildren in both urban and rural areas has been noted [3]. The analysis of the physical health of Ukrainian schoolchildren also shows that students from the city and village have common patterns and differences that depend on their place of residence [3].

Data on physical health of urban and rural schoolchildren in different regions of Ukraine, in particular taking into account the environmental characteristics, are non-systematic. Nowadays there are many papers dealing with hematological examination of schoolchildren. The researchers noted that the decrease in peripheral blood parameters does not exceed the age norms, but the tendency of their progressive decline to the limit of age norm is outlined. However, most scientific publications are stating by nature [4]. The issue of studying the state of peripheral blood in children and adolescents under the influence of environmental factors remains relevant. At the same time, the impact of the place of residence on the values of schoolchildren's blood oxygenation has not been sufficiently studied. In recent years, we have heard new terms, the definition of whichis not always clear to us. One of these terms is pulse oximetry - a method for studying hemoglobin in the blood [1].

Unfortunately, the body does not have the ability to store oxygen in the body, as it happens, for example, with adipose tissues. Therefore, the relevance of studying oxygenation is justified. This is due to the fact that the slightest disorders in the functioning of the cardiac activity, respiratory failure, and nervous system disturbances are accompanied by negative health consequences - in particular, they can cause hypoxia, that is, the lack of oxygen in the blood, and its concomitant conditions - metabolic disorders, sleep impairment, fatigue, immunity weakening, resulting in impaired physical and mental development.The purpose of the study is to study the state of oxygen saturation of schoolchildren, depending on their place of residence.

\section{Methods}

The study involved 400 healthy schoolchildren (7 and 13 years old, which is a critical age of ontogeny development). All objects were divided into groups (200 individuals in each of them), depending on their place of residence: I - rural residents (Ivanychiraion), and II - urban residents (Lutsk). There were subgroups within the groups: by age (100 persons in each) and by sex (50 persons in each). Participation in the study was voluntary. Indices of the blood oxygenation (saturation) were determined using a pulse oximeter. Pulse oximetry is a non-invasive method for monitoring the saturation of arterial blood hemoglobin with oxygen (under ideal conditions, the saturation level is within the range of 95-98\% - with this value, almost all hemoglobin is bound to oxygen). The results of pulse oximetry in the surveyed were compared with normative values: high level - above $100 \%$, low level - under 94\%; the norm is $-95-100 \%$ [1]. In the processing of the data obtained, methods of variation statistics were used to estimate Student's t-criterion with the determination of the mean value (M), the mean error $( \pm m)$, Student's reliability criterion $(t)$.

\section{Results}

Analyzing the results of the study showed that 7-year-old individuals with an increased index of bloodsaturation were absent, while its lower values were recorded in 52\% of rural children and $46 \%$ of urban ones. The results of measurements of oxygen saturation in13-year-old children indicate a significantly higher level of blood saturation in rural adolescents (boys - 95,12 $\pm 0,83 \%$, girls - 93,82 $\pm 1,21 \%$ ), compared to urban ones (boys $82,21 \pm 1.16 \%$, girls $-81.24 \pm 1.62 \%$ ). In general, it was recorded 
that 7-year-old girls were characterized by higher levels of blood saturation (group I - $88.46 \pm 0.61 \%$, group II $-90.48 \pm 0.61 \%$ ), compared to boys (group I - $82,2 \pm 0.9 \%$, group II - $89.66 \pm 0.75 \%$ ). It is interesting to note that among the surveyed living in the city, the proportion of people with normative values of blood saturation is much lower than in rural adolescents.

\section{Conclusion}

Thus, the indices of oxygen saturation are higher in 7-yearold children of the urban zone (significantly higher - in girls). Adolescents were characterized by the opposite feature - the proportion of surveyed urban areas with normative values of blood saturation is lower (up to 22\%), compared to rural schoolchildren (up to $72 \%$ ). Blood saturation affects the oxidation-reduction processes in the tissues, and therefore the metabolism and energy. However, one method cannot provide a complete picture of the state of physical health among schoolchildren. In the future, we will use additional research methods to determine the complete clinical evaluation.

\section{References}

1. Bodilovskij O (2012) Modelling of oxygen saturation signal of arterial blood. Electronics and communications 5: 24-29.

2. Gozak S (2012) Influence of educational process factors on school health indicators. Environment and health 3:17-20.

3. Dmytrotsa 0 (2015) Comparative characteristic of physical development schoolchildren indicators in urban and agrarian zones In (Eds.). 0 Dmytroca, S Shvaiko, Yu Trofimyak, Scientific Bulletin of Lesia Ukrainka East European National University, Ukraine, 2: pp. 221-228.

4. Dubey L (1999) The state of peripheral blood in children and adolescents, depending on the general level of internal radiation (Bk). Bulletin of Vinnytsia medical university 1: 72-73.
This work is licensed under Creative Commons Attribution 4.0 License

Submission Link: https://biomedres.us/submit-manuscript.php

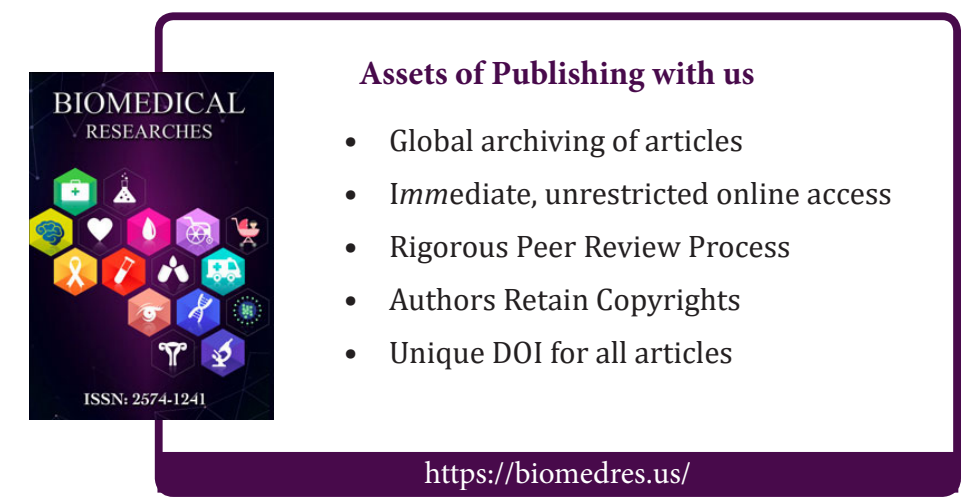

